\title{
Health Education via Television
}

\section{Three TV Series}

\section{In Washington, D. C.}

\author{
By Truman J. Keesey
}

$\mathrm{O}$

NE pert young lady closely associated with the show remarked that in terms of preparation, organization, and production it seemed like a Broadway show.

But it wasn't. It was just the Sunday night camera rehearsal for one of the television programs of the "Face to Face" series which dramatized the emotional problems of adults. This program like the one on venereal diseases and

Truman J. Keesey, writer and coproducer of the District of Columbia health TV series, is a program development specialist in the Public Health Service, assigned to the District of Columbia Department of Public Health. After his graduation from George Washington University in 1934, he taught in the District of Columbia public schools. He also was an editor of an educational research bureau.

On the succeeding pages 606 and 608 are reports of how two other local health departments-Denver and Grand Rapids, Mich.-are using television as a medium of health education. Readers interested in the current series on $T V$ are referred to Joseph Gordon's article in Public Health Reports (August 1953, p. 816) on Baltimore's experience with the 15-minute weekly TV series, "Your Family Doctor." the one on alcoholism was a pioneer health series on TV, sponsored jointly by the District of Columbia Department of Public Health and station WTOP-TV (Washington, D. C.). Each ran for 13 weeks.

\section{Time, The Essence}

Public service time is the basic requirement for a health television show (1). There are no laws or Federal Communications Commission regulations which specify that a TV station must donate any definite amount of time for public service, although in applying for their licenses, stations usually indicate how much time they expect to allocate for public service. Since many public agencies seek public service time, health departments must compete with them for the limited free time available.

In order to get public service time for health education, health officials may find it necessary, particularly in metropolitan areas, to convince television station officials that:

Information for making the people of a community healthier is of vital importance to the people themselves.

Through the presentation of health topics, they can jointly give a great public service.

They can thereby build a sizable audience for the television station and support for a health program which benefits the people of the community.

Presentation of such a program will contribute to building goodwill in the community for the station and for the health department. 
The public health program presents opportunity for developing materials and possibly techniques for the improvement of man's environment; and such materials could be used throughout the country and probably overseas as well.

No topic is so important or so interesting as the facts surrounding birth, life, human development-the actions, reactions, and interactions of people-and those leading to death. These are the substance of the bulk of all literature. Public health personnel work with these, live with them daily. There is a dynamic story for them to tell the public about these vitally important aspects of real life drama.

In approaching a station for free time, it is advisable to have at hand all possible information concerning the programs to be presented (2).

For example, when the District of Columbia station was approached for public service time for the venereal disease series, the first of the health department's TV projects, a complete format was available for the area to be covered - in each program. Following the satisfactory presentation of this first series, station WTOPTV indicated an interest in giving additional television time for health topics, and the work of the District of Columbia Department of Public Health which could be televised was then explored and discussed with station officials. The television station's program committee selected the topics for the next two series, on alcoholism and on the emotional problems of adults.

However, it isn't necessary in all negotiations to have all material as well prepared as the onepackage format for the venereal disease series. It should be expected, though, that TV station personnel will have a relatively limited knowledge of the health subjects. Their talents lie in production and presentation.

\section{Research and Planning}

After the public service time has been obtained, such detailed data as case studies can then be collected, assembled, and sifted into the various programs planned. Next, the format for each program should be arranged. Whether it will be a panel discussion, a lecture, a dra- matic presentation, or some other format will be decided, and also, whether film, charts, or graphs will be used. Wherever possible, the names of participants or a tentative list of participants should be drawn up and included with the format. A tentative timing in minutes for each aspect of the 15- or 30-minute program also should be prepared. Following is an example of a schedule for a 15-minute program:

Opening
Kitchen sequence
Narrator
Living room sequence
Narrator
Bedroom sequence 00
Narrator
Dr. Bigby
Closing

Since staff members of the health department are most familiar with the work of the department and particularly with the topical material to be covered, they are the logical ones to do the research and to prepare basic or case material for the scripts or to supervise this phase of the work.

The action we see on television in a brief 15 minutes sometimes requires months of preparation (3). Several months were devoted to research, preparing format, planning and organizing unit programs, and preparing material to be presented and publicity for each of the three series. But all material was kept sufficiently flexible so as to permit any last-minute changes.

\section{The "Face to Face" Programs}

Planning for the "Face to Face" series began more than 4 months before it opened. The planning committee was composed of representatives of the District of Columbia Department of Public Health; the District of Columbia Mental Health Association; the National Institute of Mental Health in the Public Health Service; the Office of Vocational Rehabilitation of the Department of Health, Education, and Welfare ; and St. Elizabeths Hospital (a mental institution operated by the Department of Health, Education, and Welfare). Included on this committee were psychiatrists, psychologists, psychiatric social workers, a vocational rehabilitation counselor, leaders of 
community organizations, and the health educator from the health department who was responsible for the preparation of the scripts.

Program planning sessions were held, usually 1 day a week, sometimes 2 , lasting 1 to 2 hours. Meetings were held when it was most convenient for clinic personnel. When additional case data were needed, there were occasional meetings.

Following these conferences, the health educator sifted the recommendations of the planning committee and suggested concrete proposals for the 13-weeks' series. Then, with the approval of the planning committee and WTOP-TV representatives, the preparation of scripts was begun.

At this time, the television station assigned a coproducer, a director, and a narrator to work on the show. In these joint health departmenttelevision station productions, there is a producer from each organization. Each functions as a coproducer. Since there were no public funds available for the District of Columbia series, the station assumed full financial responsibility for the programs. This underwriting did not include the preparation of scripts or production by personnel of the health departments. Moreover, in the "Face to Face" series, station personnel built sets for the various programs, and the artist worked overtime dressing up some of the sets. Because of the cost involved, the time-consuming job of shooting, editing, and preparing film for presentation, and because live shows would be more effective, it was decided to try to produce live shows.

The director of the health department's division of mental health and the regional mental health consultant of the Department of Health, Education, and Welfare, both participated in the planning sessions, and were responsible for the validity of the medical information in the scripts and in the publicity releases on the series.

After the areas to be covered in individual programs were agreed upon, titles which would attract attention were arranged for each program. Each program was designed and written to reach the community as a whole-it was not "pitched" toward any separate group. Information disseminated in the various programs had three major objectives:
To help individuals understand their emotional problems.

To tell those needing help where to find it.

'To build the much-needed support for a community program in the field of mental hygiene.

\section{Writing the Scripts}

A good script is the basis for a good show $(4-6)$. Every possible detail, such as character description, set, dialogue, action, and camera and "audio" instructions, should, therefore, be carefully thought through when preparing the script. However, it isn't necessary to include stage and camera directions. These can be left to the interpretation of the director.

From the case or basic material prepared by the psychiatrist, psychologist, and psychiatric social worker, the health educator prepared a draft script of each "Face to Face" program. To protect the identity of a patient, all case data were modified.

Copies of the draft scripts were sent to the psychiatric consultants, several leading local practitioners of psychiatry, the National Institute of Mental Health, the television station, and to the prominent individuals and specialists who "summed up" at the end of each program and the representatives of the local community agencies who appeared on the various programs. Each one scrutinized the scripts carefully and either approved them or suggested improvements.

The program director and the cast followed the script quite closely. Once the scripts were approved and turned over to the studio, no changes were permitted except those made by the director and producers, and then only for the purpose of improving the presentation. However, no tampering with the medical facts was permitted.

\section{Publicity}

In order to obtain the maximum publicity benefit, the title for the series, titles and abstracts of programs, names and identification of participants, and as many scripts as possible should be ready at least a month in advance of the starting date of the first program. 
Releases on the "Face to Face" series were sent to all local and suburban papers, wire services, science editors of newspapers and general magazines, and to such trade magazines as Billboard and Radio and Television Daily Guide, and to foundations interested in health.

\section{Casting the Mental Health Series}

The favorable reaction to the "Face to Face" series proved the effectiveness of using the people who were actually participating in the District of Columbia mental health program rather than professional actors. Two months before the series started, participants in the mental health program-many of these were clinic patients, people with emotional problems who were interested in taking part in the television programs and who were actually doing so as a part of their therapy, or members of the clinic staff-agreed to enact the roles in the series, and actually did so in all but 3 of the 13 programs. The 3 programs in which they took no part dealt with special problems in the mental health field and were done by select groups working in these special fields.

Most of the programs in the three health series were rehearsed at least once on the set, some several times, including a rehearsal with cameras. Several of the programs on alcoholism were rehearsed at least once, and sometimes twice before going to the studio for rehearsal. Health department and television station personnel do their utmost to make all program participants feel at ease on set.

Rehearsals were held in the studio for an hour once each week. The cast would walk through simulated props (property items) of their scenes and familiarize themselves with their lines and become acquainted with their fellow participants. Then, on Sunday nights, everyone reported to the studio for several camera run-throughs an hour and a half before show time.

From time to time, the cast made suggestions for improvements, occasionally changing a word or a group of words, or augmenting action to make the lines more impressive, and occasionally suggesting props or attire to improve the presentation. Their suggestions were welcomed.

\section{Use of Film and Other Aids}

Films, graphs, charts, pictures, and other objects can be used to enhance the presentation of a subject. The use of charts and graphs should be kept to a minimum.

The production of film, however, is expensive. In the venereal disease and alcoholism series, health department personnel selected the subjects to be filmed, and the studio cameraman made the shots. To save time and expense in shooting films, the director and producer should list and carefully study all selected targets. Such study may reveal that shooting some of the targets may not prove feasible. By taking all possible steps to conserve the time of the cameraman and sound engineer, production costs can be cut down.

Film was used extensively for the series on alcoholism. Although this film deteriorates slowly and can and may be used again, producing it took much time and was rather expensive. To select targets, to visit them, to set up equipment, and to shoot the scenes took time. To develop the film and to edit the scenes and to write the accompanying narration took additional time. When films are available, permission must be obtained to use cuts from them. But, compared with shooting new film, this use of films already produced requires less time and expense.

When a permanent record is desired of a television program, a film can be made of the program after it has been presented or it can be kinescoped.

Filming the show after presentation, by running through the show in its entirety before the movie camera, has better results. The film usually is better, has longer life, costs less, and bad parts may be deleted or improved by careful editing without injuring the continuity.

A live show which uses people from the various occupations in the local community as in the District of Columbia's venereal disease series, or which uses patients and clinic staff as in the series on alcoholism and emotional health is far more realistic than a filmed show. Certain aspects of a health program, such as clinic and hospital work, however, have to be presented on film unless they can be simulated in the studio. 


\section{Producing a TV Show}

Good production reflects good preparation and well-spent rehearsal time.

The final stage of production is the actual telecasting. The director assigned by the TV studio is responsible for this production stage. Although he works out preliminary details with the health department coproducer, at this point his decisions are final. From the engineers in the control room of the station through the floor manager on the set, the director manages the production personnel of the show as it goes on the air. He directs the work of the cameraman and the other technicians. The narrator performs under his supervision.

On several of the programs in the series on alcoholism, clinic personnel substituted for the narrator because the narrator was not familiar with the technical information. This substitution, however, did not work out too well: Health department staff, although knowing their material, did not present it effectively, and frequently, they were off camera (not facing the cameras). Consequently, experience has proved that it is better to have a professional narrator present the technical material in his own manner and words, making for a better presentation and also for better understanding.

\section{"VD-Very Dangerous"}

A number of considerations led the health department to seek, as a part of its educational program, the televising of the District of Columbia venereal disease story. Among these considerations were a reduced budget which affected the venereal disease contact investigation program, the lagging interest of many persons who had taken an active part in a citizens committee for venereal disease control, and a need to emphasize to the public that there still was a serious venereal disease problem in the District.

Moreover, it was thought to be particularly important to try to reach the late adolescent group, which was known to have the highest incidence of venereal disease.

These points had been repeatedly stressed by staff members of the health department's bureau of venereal diseases in talks before various community organizations and also through the press and over radio and television. It was necessary to reach the general public with these facts so as to emphasize the problem to the large numbers of people affected in the community. Television provided the means of realizing this objective.

Station officials at WTOP-TV, becaluse of their experience with venereal disease radio programs, believed that the subject of venereal disease could be presented in good taste and with dignity. The station officials approved the general plan outlined by the health department, allotted the time, and furnished a narrator from the station to work with health department personnel. After these preliminary negotiations had been completed, production began on "VD-Very Dangerous," the venereal disease series.

In Washington, D. C., community responsibility for venereal disease control had been placed in the cosmopolitan, representative Citizens Committee for Venereal Disease Control. The various programs of the TV series on venereal disease used members from this committee along with officials of the health department and private practitioners of medicine to reemphasize the necessity for continuing community responsibility for venereal disease control.

The street interviews used on one program proved to be one of the most interesting bits of television camera work done in the entire series. To determine how much the average person knew about venereal disease and whether he was willing to talk about it, it was decided to stop Mr., Mrs., and Miss Washington on the downtown streets and question them about the subject. Everyone involved in the street scenes-narrator, cameraman, engineer, producer, and others-was due for a surprise. Practically all persons stopped, responded to the questions, and revealed that they did have some knowledge of venereal disease.

\section{Alcoholism-"The Road Back"}

From the viewpoint of community education and responsibility, there was a great difference between the planning and organization for the venereal disease control program and the alcoholic rehabilitation program: 
There was a paucity of health education media on alcoholism-printed materials, motion pictures, recordings, and other information aids-as compared with the variety and quantity of materials available for venereal disease education.

There are a large number of alcoholics who, while appearing regularly before the courts, do not get treatment. Venereal disease control has no such court problem.

And, finally, there was no committee working for the rehabilitation of alcoholics such as the one actively interested in venereal disease control and broadly representing community leadership. There was, therefore, a greater need for education in the cause of alcoholism and about the services and facilities of the alcoholic rehabilitation program of the District of Columbia.

Program personnel met regularly and often with a committee from the health department's alcoholic rehabilitation program clinic. The committee was composed of a psychiatrist, psychologist, psychiatric social worker, and nurse. These sessions lasted from 1 to 2 hours and were held weekly during a 10 -week period preceding the start of the series. There were only occasional meetings of this group after the series started, but the producers met weekly with a staff psychiatrist and others who were scheduled to appear on the programs.

The alcoholism TV series, titled "The Road Back," emphasized the fact that the alcoholic is a sick person, needing medical care in the same way as a person sick with tuberculosis or heart disease. The programs concentrated on alcoholic patients and the people who work with them-physicians, psychiatrists, psychologists, social workers, nurses, and occupational therapists.

Rehabilitated alcoholic patients participated in 10 of the 13 programs, enacting the roles involved in the 4 representative cases which had been carefully prepared by the clinic staff and which were followed throughout most of the 10 programs. The title and subtitles for the series were more subtle than the more obvious titles of the venereal disease programs. Two of the programs were panel discussions, and a third show was on film.
In "Road Block," the first program, the audience was presented with the problem of the chronic drinker. In the succeeding programs, the viewer was taken step by step through the intake interview, diagnostic interview, psychological testing, and individual and group therapy, showing their application to the reestablishment of the alcoholic as a producer in the community life. A program on psychodrama as a technique of therapy was also included in the series. The concluding program in the series urged that:

Problem drinkers go for help either to their family physician, Alcoholics Anonymous, or the clinic of the District of Columbia alcoholic rehabilitation program.

Rehabilitated alcoholics and others taking treatment be given jobs commensurate with their capacity to produce and at pay which would permit living in good health and decency.

A municipal facility with separate quarters for men and women be provided where alcoholics on the "road back" may stay until they get on their feet.

Private hospitals admit alcoholics.

An intensified educational program be developed.

A broad citizens committee for rehabilitation of alcoholics be organized.

The District of Columbia establish an alcoholic rehabilitation farm for work and the multiple therapy techniques used in the treatment of mental health patients.

\section{Audience Reaction}

American University's Bureau of Social Science Research (Washington, D. C.) conducted a limited survey to determine audience reaction to the venereal disease series. The survey revealed that the programs had "served to stimulate a slight increase in clinic attendance." The percentage of new admissions who had recently viewed the venereal disease programs over television, it was found, increased from $21 / 2$ percent in October to 4 percent in November 1952. There was an additional increase of 1 percent in December 1952.

Telepulse surveys are conducted on a doorto-door basis and in the same manner as Census Bureau surveys. The percentage of listeners to 
a television program is computed on the basis of the total number of sets the station reaches in the listening area at the time the survey is made.

Despite late presentation time, the 3 health series, although in competition with 2 feature movies almost consistently, had the largest audience. One survey conducted the first week in December 1952 revealed the following:

\begin{tabular}{|c|c|}
\hline & $\begin{array}{r}\text { Percent } \\
64\end{array}$ \\
\hline on $\mathrm{B}$ & Feature film \\
\hline $\mathrm{C}$ & Feature film \\
\hline ion $\mathrm{D}$ & 2.0 \\
\hline
\end{tabular}

At the time of the December 1952 survey, there were an estimated 410,000 TV sets in the Washington area. On the basis of the average number of listeners per set-an estimated 13/4 persons per set viewing a program-multiplied by the 6.4 percent of the television-listening audience, it is estimated that 45,920 persons were viewing the venereal disease series during the survey. The surveys for the other series showed similar audience response.

Both the television station and the health department received requests for help with personal problems and for literature on the subject of mental hygiene. Scripts already have been sent to 60 national, State and local, public and private, health agencies, and to universities, public school systems, and private industrial and business organizations. Requests for scripts also included one from a State medical society and a national television system outside the United States.

Scripts of the various venereal disease programs have been sent to all of the State and Territorial health departments and to some local health departments and also to health officials in countries of Africa, Asia, Europe, and Latin America. Some of the State and local requests for scripts resulted from the publicity the series received.

\section{Summary and Conclusions}

This has been the District of Columbia's experience with three television series, dealing with two different types of public health problems-one a physical problem, venereal disease in terms of community education and treatment at an advanced stage, the other two dealing with mental illness.

Favorable public reaction to these three series and to health topics presented over television reflects the great public interest in health generally and particularly in health programs on television.

In order to hold the attention of viewers and to increase their number, health programs must be well-planned, factually correct, well-organized, and well-presented. In order to make health programs more acceptable, they should be dramatized-health and medical facts should be presented so that they simultaneously are both enlightening and entertaining.

The maximum of cooperation and harmony between professional disciplines of the medical field and TV station personnel are essential for a successful production. This means the harmonious work, on the one hand, of physicians, psychologists, nurses, social workers, and scriptwriter or health educator, and, on the other, of the director and producer representing the television station.

\section{REFERENCES}

(1) Mabley, J.: What educational TV offers you. Public Affairs Pamphlet No. 203. New York, N. Y., The Public Affairs Committee, Inc., 1954.

(2) Hodapp, W. C.: Television manual. New York, N. Y., Farrar, Straus, and Young, 1953.

(3) Hubbell, R. W.: Television programing and production. New York, N. Y., Rinehart and Company, 1950.

(4) Seldes, G. V.: Writing for television. New York, N. Y., Doubleday and Company, 1952.

(5) Kaufman, W. I., and Colodzin, R. S. : Your career in television. New York, N. Y., Merlin Press, 1950.

(6) Greene, R. S.: Television writing; theory and technique. New York, N. Y., Harper and Brothers, 1952. 